\title{
Pesticide exposure of pregnant women in Guadeloupe: Ability of a food frequency questionnaire to estimate blood concentration of chlordecone
}

\author{
Laurence Guldner, $^{\mathrm{a}, \mathrm{b}}$, Luc Multigner $^{\mathrm{a}}$, Fanny Héraud $^{\mathrm{c}}$, Christine Monfort $^{\mathrm{a}}$, Jean Pierre Thomé ${ }^{\mathrm{d}}$, Arnaud Giusti $^{\mathrm{d}}$, \\ Philippe Kadhel $^{\mathrm{a}, \mathrm{e}}$, Sylvaine Cordier ${ }^{\mathrm{a}}$ \\ a INSERM U625, GERHM, Université Rennes 1, IFR 140, 35042, Rennes, France \\ ${ }^{b}$ National Institute of Public Health Surveillance (InVS), DSE, 94415 Saint Maurice, France \\ ${ }^{c}$ Office of Scientific Support to Risk Assessment, French Food Safety Agency (AFSSA), Maisons-Alfort, France \\ ${ }^{d}$ Laboratory of Animal Ecology and Ecotoxicology, CART, Liège University, Liège, Belgium \\ ${ }^{e}$ Department of Gynecology and Obstetrics, University Hospital, Pointe à Pitre, Guadeloupe, France
}

\begin{abstract}
Context: Chlordecone, an environmentally persistent organochlorine insecticide used intensively in banana culture in the French West Indies until 1993, has permanently polluted soils and contaminated foodstuffs. Consumption of contaminated food is the main source of exposure nowadays. We sought to identify main contributors to blood chlordecone concentration (BCC) and to validate an exposure indicator based on food intakes.
\end{abstract}

Material and methods: We used a food frequency questionnaire (FFQ) completed by a sample of 194 pregnant women to estimate their dietary exposure to chlordecone and compared it to blood levels. In a first approach, chlordecone daily intake was estimated as the product of daily eaten quantity of 214 foodstuffs, multiplied by their chlordecone content, and summed over all items. We then predicted individual blood chlordecone concentration with empirical weight regression models based on frequency of food consumption, and without contamination data.

Results: Among the 191 subjects who had BCC determination, 146 (76\%) had detectable values and mean BCC was $0.86 \mathrm{ng} / \mathrm{mL}$ (range < LOD-13.2). Mean per capita dietary intake of chlordecone was estimated at $3.3 \mu \mathrm{g} / \mathrm{day}$ (range: 0.1-22.2). Blood chlordecone levels were significantly correlated with food exposure predicted from the empirical weight models $(r=0.47, p<0.0001)$ and, to a lesser extent, with chlordecone intake estimated from food consumption and food contamination data $(r=0.20, p=0.007)$. Main contributors to chlordecone exposure included seafood, root vegetables, and Cucurbitaceous.

Conclusion: These results show that the Timoun FFQ provides valid estimates of chlordecone exposure. Estimates from empirical weight models correlated better with blood levels of chlordecone than did estimates from the dietary intake assessment.

Keywords: Chlordecone; Organochlorine pesticides; Dietary intake; Food frequency questionnaire; Guadeloupe; Pregnancy

\section{INTRODUCTION}

Bananas are intensively cultivated in the French West Indies (Martinique and the Guadeloupe archipelago). Substantial quantities of pesticides are used to control insects, nematodes, and fungi in these plantations. From the early 1970s until 1993, chlordecone, an organochlorine insecticide, was used extensively and almost exclusively to control banana root borers (Cellule interregionale d'epidemiologie Antilles Guyane, 2005). Its strong resistance to biotic and abiotic degradation has resulted in continuing soil pollution (Cabidoche et al., 2006), which contaminates some local water and food sources (AFSSA, 2005, 2007). Recent data show that chlordecone is present in the blood of adult men, pregnant women, and newborns in Guadeloupe (Multigner, 2006; Multigner et al., 2006, 2007). Given the discontinuation of chlordecone use since 1993, nowadays its principal source is thought to be contaminated foodstuffs (Dubuisson et al., 2007). 
In humans, chlordecone exposure in occupational circumstances has been associated with a well recognized clinical syndrome involving the nervous system, liver, and testes (Cannon et al., 1978; Cohn et al., 1978; Taylor et al., 1978). Experimental studies in animals confirm all of the toxic effects observed in humans (Faroon et al., 1995). Moreover, gestational and perinatal chlordecone exposures in rodents have been shown to be detrimental to normal fetal development and to impair normal neurobehavior during pre- and post-weaning development (Gellert, 1978; Mactutus and Tilson, 1984; Mactutus et al., 1984; Faroon et al., 1995). Despite numerous experimental studies, the impact of chlordecone exposure at environmental levels on fetal and postnatal development in humans has never been investigated. A prospective epidemiological mother-child cohort (TIMOUN study) is currently being followed in Guadeloupe in order to study the impact of prenatal chlordecone exposure on pregnancy outcome and infant development. Assessment of the health consequences for this population requires the validation of useful chlordecone exposure indicators. Today, exposure can be accurately assessed by measuring chlordecone concentrations in blood (serum or plasma). This study aimed to identify principal determinants and food contributors to chlordecone exposure. Moreover, two indirect indicators of chlordecone exposure based on dietary habits were validated on a sample of pregnant women, whose chlordecone blood levels were also measured.

\section{MATERIAL AND METHODS}

\subsection{Area, population, and study design}

Guadeloupe comprises five islands, the most important of which are Grande-Terre and Basse-Terre, separated by a narrow sea channel. The banana plantations and soils polluted by chlordecone are mostly located in the southern part of Basse-Terre. This analysis was conducted in the ongoing TIMOUN cohort study. Enrolled subjects were representative of pregnant women giving birth in the local public hospitals (one in Grande-Terre and one in Basse-Terre), which account for $70 \%$ of all deliveries in Guadeloupe. Obstetricians enrolled women in this cohort during the second trimester prenatal visit, from December 2004 through December 2007. At enrollment, they provided informed consent and completed, during face-to-face interview with midwives, a standardized questionnaire covering sociodemo-graphic characteristics, medical and obstetrical history, and lifestyle. This questionnaire also included 6 items about prepregnancy frequency of consumption of foods known to be contaminated by chlordecone (fish and root vegetables (AFSSA, 2007)). Women included in the present analysis were the first 194 for whom both food consumption data and blood chlordecone determinations were available.

\subsection{Collection of data about food consumption habits}

During the 3-5 days of hospitalization following delivery, a semiquantitative food frequency questionnaire (SQFFQ), asking about usual dietary intake during this pregnancy, was administered to the women by trained interviewers.

The SQFFQ was developed from a questionnaire covering 105 food items used in two previous general population studies in Martinique and Guadeloupe (Dubuisson et al., 2007). This initial questionnaire was intended to identify consumption of potentially contaminated food only and was thus completed by 109 other food and beverage items, including tap and bottled water (totaling 214) to provide an exhaustive assessment of maternal diet and nutrient intake (Willett, 1998b).

Categories for frequency of consumption were: never, less than once a month, 1 to 3 times a month, once a week, 2 or 3 times a week, 4 or 5 times a week, once a day, and more than once a day. Responses were further translated into the corresponding median number of meals a month for each item. Portion sizes were evaluated with the help of a booklet of pictures for the principal 11 food categories: raw vegetables, cured meats, meat, fish, root vegetables, other cooked vegetables, French fries, starches (pasta, rice, and semolina), bread, cheese, and desserts. Pictures and portions for these categories were extracted and adapted from a booklet used in the French SU.VI.MAX survey (Hercberg et al., 1994).

Reported energy intake was calculated by matching food consumption data and food composition data, derived from a French table (Hercberg, 2005) and completed with the Canadian (Health Canada, 2007) and the US (USDA, 2007) food composition tables. Subjects eating fewer than $800 \mathrm{kcal}$ or more than $6000 \mathrm{kcal}$ per day $(n=3)$ were excluded because their SQFFQ responses were considered unreliable (Willett, 1998b). 


\subsection{Dietary chlordecone intake assessment}

Data about chlordecone levels in food come from a survey conducted in Guadeloupe from July 2006 to July 2007 (AFSSA, 2007). This survey was designed to assess the dietary intake of chlordecone in the general population older than 3 years, according to the WHO guidelines (FAO/WHO, 1997, 2000). Factors considered in planning the types and numbers of samples to collect included the known contribution of foods to dietary chlordecone intake and the importance in the Caribbean diet of food items for which chlordecone contamination is not known. Local retailers and markets were divided into two strata based on their location in a polluted or an unpolluted area. The sampling places were drawn according to the food supply habits of the population, as described in the food consumption survey, with the same rate for each stratum (AFSSA, 2007). Self-production was also taken into account. European Union (directive 2002/63/ EC) guidelines establishing community methods of sampling for the official control of pesticide residues in and on products of plant and animal origin were applied to collect the 744 food samples. Analytical methods and quality control have been described elsewhere (Bordet et al., 2007). Data were expressed as mean concentrations ( $\mu \mathrm{g} / \mathrm{kg}$ of fresh product) stratified according to the area where they were sampled (polluted or unpolluted areas of the island). The relations between the 59 items for which contamination data were available and items in the SQFFQ were determined to help attribute chlordecone values to the latter. When no information was available, assumptions were based on the same principles as those defined in previous dietary intake assessment studies (AFSSA, 2007).

Daily dietary intake of chlordecone was assessed for each subject according to a previously described procedure (AFSSA, 2007). The quantity of each food (or beverage) item eaten daily was multiplied by its mean estimated chlordecone level. Estimated quantities of chlordecone intake from all 214 items were then summed to obtain a total daily intake ( $\mu \mathrm{g} / \mathrm{day})$. We designate this as the food consumption-food contamination approach (FCFC).

\subsection{Other covariates}

The following information was obtained from a questionnaire administered at enrollment: maternal age, place of birth (Guadeloupe, Martinique, Haiti, Dominica, continental France), town of current residence, marital status, educational level (none, primary, secondary school, high school diploma, higher education), employment status before pregnancy, weight and height before pregnancy, obstetrical history, previous breast-feeding, and smoking status. Body mass index was calculated as weight $(\mathrm{kg}) /(\text { height }(\mathrm{m}))^{2}$ and classified as underweight $(<18.5$ $\left.\mathrm{kg} / \mathrm{m}^{2}\right)$, normal $\left(18.5-<25 \mathrm{~kg} / \mathrm{m}^{2}\right)$, overweight $\left(25-<30 \mathrm{~kg} / \mathrm{m}^{2}\right)$, or obese $\left(\geq 30 \mathrm{~kg} / \mathrm{m}^{2}\right)$. Risk of residential contamination was determined by matching women's town of current residence with the most recent map of soil pollution risk in Guadeloupe (Cabidoche et al., 2006), drawn by matching land plots to past and present maps of banana plants. The risks thus defined were further validated by soil analyzes.

\subsection{Chlordecone blood determination}

At delivery, maternal blood samples were collected in EDTA tubes. After centrifugation, they were transferred to polypropylene Nunc ${ }^{\circledR}$ tubes and stored at $-30{ }^{\circ} \mathrm{C}$. Blood samples were transferred in dry ice to the Laboratory of Animal Ecology and Ecotoxicology (Liege, Belgium) which is a member of the Center for Trace Residue Analysis (CART) for determination of chlordecone concentrations.

Blood samples were prepared by adaptation of a previously described method (Debier et al., 2003). Briefly, blood was first treated by adding $100 \mu \mathrm{L}$ of triethylamine and $10 \mathrm{~mL}$ of formic acid to a precisely known volume of sample (from 2 to $3 \mathrm{~mL}$, depending on the amount of sample initially available). Solid phase extraction used Supelco Supelclean ${ }^{\mathrm{TM}}$ Envi-18 SPE Tubes (Supelco, Bellefonte, PA, USA). An elution device (Visiprep DL ${ }^{\mathrm{TM}}$ SPE Supelco) was used to condition the column with $10 \mathrm{~mL}$ methanol, followed by $10 \mathrm{~mL}$ of distilled water. The deproteinized sample was added to the column and rinsed with distilled water and dried under vacuum. After a first elution by $5 \mathrm{~mL}$-hexane, a second elution was performed, with the addition of $5 \mathrm{~mL}$ diethylether/n-hexane $(85 \% / 15 \%, v-v)$ and $50 \mu \mathrm{L}$ of PCB $112(100 \mathrm{pg} / \mu \mathrm{L})$, used as a surrogate marker. Then the sample was evaporated and purified by concentrated sulfuric acid. The purified extracts were evaporated under a gentle nitrogen stream to a final volume of $100 \mu \mathrm{L}$. The extracts were analyzed by high-resolution gas chromatography, with a Thermo Quest Trace 2000 gas chromatograph equipped with a Ni ${ }^{63}$ ECD detector (Thermo Quest, Milan, Italy). Chlordecone was separated on a $30 \mathrm{~m}$ x $0.25 \mathrm{~mm}(0.25 \mu \mathrm{m}$ film $)$ DB-XLB capillary column (J\&W Scientific, Santa Clara, CA, USA). The linear calibration curve, with concentrations ranging from 5 to $120 \mathrm{pg} / \mu \mathrm{L}$, was established with a certified chlordecone solution (Riedel-de Haën). A blank consisting of $2 \mathrm{~mL}$ of distilled water was run with each series of 10 samples to control the cleanup procedure. A quality control sample of human blood enriched with a defined concentration of chlordecone was run and analyzed simultaneously. Recovery was calculated on the basis of the concentration of surrogate marker PCB $112(50 \mathrm{pg} / \mu \mathrm{L})$. The results of the analyzes were accepted only for recoveries between $70 \%$ and $130 \%$. Due to the high remanence of chlordecone molecules on the analytical column, a calculation strategy had to be used. With each series analyzed, n-hexane samples were injected before and after the blank sample and another hexane was injected after the injection of 5 samples. In those hexanes a peak corresponding to the chlordecone released 
by the column was found and processed as a sample. The average value found in those hexane samples was considered as the average remanence of chlordecone in the series of concern. This value was then subtracted from the chlordecone concentration value of each sample in order to better avoid the chlordecone remanence. In these conditions, the limit of detection (LOD) was fixed at triple the background noise of the chromatogram, which corresponds to the hexane samples average value. The limit of quantification (LOQ) was determined by means of spiked blood serum samples and was the lowest concentration that could be quantified. In our analytical conditions, the LOD was 0.25 and the LOQ $0.75 \mathrm{ng} / \mathrm{mL}$ Mean and standard deviation of chlordecone blood level were estimated using the maximum likelihood estimation (MLE) approach, which is a relevant procedure when dealing with left-censored data.

\subsection{Statistical analysis}

\subsubsection{Predictive model of BCC building}

Previous studies have underlined some limitations of the FCFC approach to explain blood levels of vitamin E (Romieu et al., 1990) or toenail arsenic (Macintosh et al., 1997) and have shown improved correlation with empirical weights models (EWMs; Willett, 1998a). Consequently, we also explored EWM for predicting total chlordecone exposure. This procedure is based on predictive models of blood chlordecone levels including the frequency of consumption of food items as predictors, independent of their level of contamination.

In order to build predictive models of BCC, we adapted initial model building from Macintosh et al. (1997), Romieu et al. (1990), and Riederer et al. (2008). All models were adjusted on the blank of the analysis batch, in order to assess the predictive value of potential predictors apart from laboratory variability. Model building involved the following steps.

\subsubsection{Step 1: Construction of a list of potential diet predictors of chlordecone exposure.}

We first selected, among the 214 food items originally included in the SQFFQ those that contributed to more than $0.5 \%$ of the total daily dietary intake of chlordecone, as estimated with the FCFC approach. This percentage value was chosen with the goal of including both relatively few candidate food items in the multivariate analysis and those that are relevant contributors to actual intake.

\subsubsection{Step 2: Selection of non-diet covariates.}

Non-diet covariates (sociodemographic, anthropometric, and obstetric characteristics) were then included in a multivariate Tobit regression model using proc lifereg in SAS (Tobin, 1958; Lubin et al., 2004; Zeghnoun et al., 2007), with $\log$ transformed BCC as a dependent variable, censored at the detection limit $(0.25 \mathrm{ppb})$. Items with p-values $\leq 0.2$ in this multivariate model were selected for step 3 .

\subsubsection{Step 3: Multi-stage selection of diet predictors.}

We then made a selection of diet predictors of BCC by running Tobit regression models of $\log \mathrm{BCC}$ on homogenous lists of foods as selected in step 1, and grouped as follows: seafood products, meat products, root vegetables, other vegetables, fruits, dairy products, and beverages. Blank of the analysis batch and non-diet covariates selected in step 2 were also forced in these models. Food consumption frequencies were included as indicator variables of tertiles of continuous variables, omitting the lowest one. Items with $p$-values $\leq 0.2$ in each of these multivariate models were selected for step 4.

\subsubsection{Step 4: Final model selection.}

All diet and non-diet items selected in steps 2 and 3 were introduced together into a Tobit regression model with $\log$ BCC as a dependent variable. Those with $p$-values $>0.2$ were successively discarded. Potential predictors discarded in steps 2 and 3 where then introduced one at a time in this last model and allowed to re-enter it if $p<$ 0.2 . At last, a manual backwards selection $(p<0.2)$ was performed to obtain the final model with major predictors.

Collinearity diagnoses were made using COLLIN option in STATA software. Normality and homoskedasticity of the model residuals were evaluated by examining histograms of standardized residuals and plots of predicted values versus standardized residuals.

Statistical analyzes were performed with SAS software version 9.1 (SAS Institute, Inc., Cary, North Carolina) and STATA software version 9.2 (Statacorp LP, College Station, USA).

\subsubsection{Validity of FCFC estimate and predicted BCC}

The validity of daily chlordecone intake and predicted BCC as predictors of the total exposure was assessed by computing partial Spearman correlation coefficients between BCC and the two indirect estimates, adjusted for the blank of the analysis batch. We also compared the distribution into quintiles of blood chlordecone levels, 
FCFC estimates, and predicted BCC. The percentage of women classified in the same or in an adjacent quintile by both methods was chosen as a criterion to evaluate the potential utility of indirect dietary assessment of chlordecone exposure.

\section{RESULTS}

To date, 194 women in this ongoing cohort have completed the SQFFQ and had blood chlordecone determined. Three were excluded because their estimated energy intake was out of the $800-6000 \mathrm{kcal} / \mathrm{day}$ range. The following analyzes thus concern 191 women.

\subsection{Main characteristics of the study population}

Mean age at enrollment was 31.4 years (range: 16.8-48.8). Seventy-five percent of them were born in the French West Indies, $11 \%$ in Haiti or Dominica, and 14\% in continental France. Most of the subjects (75\%) were recruited at the University Hospital of Pointe a Pitre, in Grande-Terre. One third of the population (30\%) lived in polluted areas. More than half $(55 \%)$ had not completed a high school diploma. Mean BMI at the beginning of pregnancy was 24.7 (range: 15.1-49.8); 25\% were classified as overweight and 15\% as obese. Mean daily caloric intake during pregnancy was $2846 \mathrm{kcal}$ (range: 951-5959). Of the 109 multiparous women, $89 \%$ had previously breast-fed. On average, women ate meat products (beef, veal, pork, cooked meats, offal, poultry, and eggs) 1.6 times a day, seafood (fish, shellfish, and fish-based products) 1.0 times a day, vegetables 4.3 times a day, including roots and tubers 1.6 times a day, dairy products (milk, yogurts, cheese) 3.2 times a day and fruit 3.6 times a day.

Consumption of meat, fish, and root vegetables before pregnancy (as reported in the enrollment questionnaire) and during pregnancy (as reported in the SQFFQ administered at delivery), did not appear to change.

\subsection{FCFC estimate of chlordecone exposure}

According to the FCFC approach, the mean estimated dietary chlordecone intake was $3.3(0.1-22.2) \mu \mathrm{g} / \mathrm{day}$. Women living in unpolluted areas had an intake of $1.9(0.1-20.6) \mu \mathrm{g} /$ day while for those in polluted areas it was $6.6(1.0-22.2) \mu \mathrm{g} /$ day. Of the 214 food items, 22 individual items contributed to more than $0.5 \%$ of total exposure (Table 1). These items included mainly seafood ( $40 \%$ of total intake), root vegetables ( $30 \%$ of total intake), Cucurbitaceae (10\% of total intake), and some other fruits, vegetables, and meats.

The blank-adjusted partial Spearman correlation coefficient between log-transformed blood chlordecone levels and estimated average dietary chlordecone intake was $0.20(p=0.007)$. Comparing the distribution into quintiles of blood chlordecone levels and the FCFC estimates, we found $56 \%$ of the women classified by both in the same or in an adjacent quintile, $3 \%$ being classified in opposite quintiles (Table 3).

\subsection{Chlordecone levels in maternal blood samples}

Chlordecone was detected in $76 \%$ of the maternal blood samples, with a mean concentration (MLE estimate) of $0.86 \mathrm{ng} / \mathrm{mL}$ (range: < LOD -13.2). 


\subsection{Potential nondietary predictors of blood chlordecone levels}

Women living in unpolluted areas had lower blood chlordecone levels $(0.82 \mathrm{ppb})$ than those living in polluted areas (1.02 ppb, $p=0.01)$. We found no significant differences in blood chlordecone levels according to age, marital status, educational level, employment status, weight, height, BMI, parity, previous breast-feeding or smoking.

\subsection{Predicted BCC}

Table 2 presents the empirical weight model selected, with its beta coefficients and their p-values. Seven women were excluded from regression analyzes because their city of residence in Guadeloupe was unknown, and they could not be classified as living in unpolluted or polluted area of the island. Along with the place of residence (polluted or unpolluted area), 7 dietary predictors of the 22 previously selected were associated with blood chlordecone levels. The blank-adjusted partial Spearman correlation between the blood chlordecone levels as measured and the predicted values was 0.47 ( $p<0.0001)$. Comparing the distribution into quintiles of measured and predicted blood chlordecone levels, we found $70 \%$ of the women classified by both in the same or in an adjacent quintile, and $1 \%$ classified in opposite quintiles (Table 3 ).

Table 1: Main contributors to total daily chlordecone intake, as estimated by the FCFC approach.

\begin{tabular}{|l|c|}
\hline \multicolumn{1}{|c|}{ Food item } & Percent \\
\hline Creel and net fishes & 24.6 \\
\hline Fresh water crustaceans & 12.6 \\
\hline Yautia & 8.7 \\
\hline Sweet potatoes & 8.2 \\
\hline Cucumbers & 6.8 \\
\hline Taro & 6.7 \\
\hline Cabbage & 4.3 \\
\hline Beef burger & 3.4 \\
\hline Carrots & 3.0 \\
\hline Beef & 3.0 \\
\hline Pelagic fishes & 2.2 \\
\hline Spring onions & 2.1 \\
\hline Tomatoes & 1.7 \\
\hline Giraumon squash & 1.5 \\
\hline Avocados & 1.4 \\
\hline Melon & 1.4 \\
\hline Yams & 1.2 \\
\hline Watermelon & 0.8 \\
\hline Partly skimmed milk & 0.8 \\
\hline Tap water & 0.8 \\
\hline Veal & 0.7 \\
\hline Local apples (sapodilla, sugar apple) & 0.6 \\
\hline
\end{tabular}


Table 2: Empirical weight model derived from the percentage contribution method for the selection of candidate food items, $N=184$.

\begin{tabular}{|c|c|c|}
\hline Food item & $\beta$-coefficient ${ }^{\mathrm{a}}$ & $p$-value \\
\hline \multicolumn{3}{|l|}{ Area of residence } \\
\hline Unpolluted & Ref. & Ref. \\
\hline Polluted & 0.41 & 0.005 \\
\hline \multicolumn{3}{|l|}{ Crustaceans } \\
\hline Tertile 0 & Ref. & Ref. \\
\hline Tertile 1 & 0.12 & 0.441 \\
\hline Tertile 2 & 0.31 & 0.066 \\
\hline \multicolumn{3}{|l|}{ Yautia } \\
\hline Tertile 0 & Ref. & Ref. \\
\hline Tertile 1 & 0.02 & 0.902 \\
\hline Tertile 2 & 0.46 & 0.008 \\
\hline \multicolumn{3}{|l|}{ Spring onion } \\
\hline Tertile 0 & Ref. & Ref. \\
\hline Tertile 1 & 0.34 & 0.028 \\
\hline Tertile 2 & 0.39 & 0.015 \\
\hline \multicolumn{3}{|l|}{ Cucumber } \\
\hline Tertile 0 & Ref. & Ref. \\
\hline Tertile 1 & -0.36 & 0.036 \\
\hline Tertile 2 & 0.23 & 0.108 \\
\hline \multicolumn{3}{|l|}{ Water melon } \\
\hline Tertile 0 & Ref. & Ref. \\
\hline Tertile 1 & 0.24 & 0.150 \\
\hline \begin{tabular}{|l|} 
Tertile 2 \\
\end{tabular} & 0.11 & 0.538 \\
\hline \multicolumn{3}{|l|}{ Avocado } \\
\hline Tertile 0 & Ref. & Ref. \\
\hline Tertile 1 & 0.06 & 0.715 \\
\hline Tertile 2 & -0.23 & 0.075 \\
\hline \multicolumn{3}{|l|}{ Beef burger } \\
\hline Tertile 0 & Ref. & Ref. \\
\hline Tertile 1 & -0.50 & 0.0003 \\
\hline Tertile 2 & -0.35 & 0.038 \\
\hline
\end{tabular}

${ }^{a}$ Adjusted for the blank of analysis batch.

Table 3: Comparison of BCC and indirect estimates of dietary exposure to chlordecone.

\begin{tabular}{|l|c|c|c|c|}
\hline \multicolumn{1}{|c|}{ Estimate } & $\begin{array}{c}\text { Partial blank-adjusted } \\
\text { Spearman correlation with } \\
\end{array}$ & \multicolumn{2}{|c|}{$\begin{array}{c}\text { Classification of the subjects according to quitiles of BBC } \\
\text { distribution and the indirect estimates }(n, \%)\end{array}$} \\
\cline { 2 - 5 } & Same quintile & Adjacent quintiles & Extreme quintile \\
\hline FCFC estimate & $0.20(0.007)$ & $37(20.1)$ & $66(35.9)$ & $6(3.3)$ \\
\hline $\begin{array}{l}\text { Predicted value } \\
\text { from EWM }\end{array}$ & $0.47(p<0.0001)$ & $53(28.8)$ & $76(41.3)$ & $2(1.1)$ \\
\hline
\end{tabular}




\section{DISCUSSION}

This study makes it possible for the first time to compare the body burden of chlordecone as estimated by blood measurement and by dietary intake, estimated through a food frequency questionnaire. Blood chlordecone levels have been recognized as a relevant method for estimating body burden in humans (Guzelian, 1992). This study showed that more than three fourth of a representative sample of pregnant women in Guadeloupe had detectable blood chlordecone levels. The range of values ( < LOD to $13.2 \mathrm{ng} / \mathrm{mL}$ ) is consistent with a previous estimate in a similar population of pregnant women in Guadeloupe (< LOD to $16.6 \mathrm{ng} / \mathrm{mL}$; Multigner, 2006).

Women living in polluted areas had higher blank-adjusted log-transformed blood chlordecone levels than those in unpolluted areas, perhaps due to their higher intake of locally grown food that was more highly contaminated.

The fact that previous lactation was not associated in our study with significant differences in blood chlordecone levels can be explained by this chemical's plasma transport process and tissue distribution pattern. Because chlordecone is transported in blood by albumin and HDL lipoproteins (Soine et al., 1982), peripheral fat tissue accumulation is relatively low. It thus differs from other organochlorine pesticides, which bind preferentially to VLDL and LDL lipoproteins and are preferentially distributed to fat tissues (Gomez-Catalan et al., 1991; Soine et al., 1982). Moreover, preliminary studies confirm that even when blood chlordecone levels are high, much lower levels are excreted in human milk (Multigner, 2006).

Chlordecone exposure predictors, estimated from SQFFQ by either the FCFC or the EWM approach, were significantly positively correlated with blood chlordecone levels. This is consistent with the fact that food and water are the source of chlordecone exposure in Guadeloupe today, since chlordecone use ended in 1993. These results show that the food frequency questionnaire discriminates well between subjects with different blood chlordecone levels.

The SQFFQ included an exhaustive list of foods, with quantitative evaluation of the main categories. It seems unlikely that major contributors were omitted from the list of foods. It is possible, however, that certain items may have been misreported by women, for this bias is inherent in food frequency methods. Administration of the questionnaire by trained interviewers, at a moment when the women were alone and not busy, was intended to minimize diet reporting errors. This questionnaire about diet during pregnancy was administered after delivery. Because we cannot rule out the possibility that some biological contamination may have been determined by prepregnancy diet, we compared consumption data at delivery with global frequency of consumption before pregnancy of meat, fish, and root vegetables. The absence of any changes in intake of these items indicates that at least for the principal chlordecone contributors, the diet recorded at delivery was probably representative of the prepregnancy diet.

When related to the weight of each subject, mean chlordecone dietary intake in the pregnant women was estimated at 0.09 for women living in polluted areas and $0.03 \mu \mathrm{g} / \mathrm{kg}$ body weight $/$ day for those in unpolluted areas. This is consistent with a previous assessment in the general Guadeloupean population (age over 16; AFSSA, 2007). The correlations between blood chlordecone level as an exposure bio marker and either FCFC estimates $(r=0.20)$ or EWM estimate $(r=0.47)$ were in the range of previous studies. In a US study, Macintosh et al. (1997) found correlation coefficients of 0.15 and 0.25 , respectively, between toenail arsenic ( $N=785$ subjects) and either FCFC or EWM estimates, and around 0.35 between toenail mercury ( $N=969$ subjects) and either FCFC or EWM.

Nevertheless, several factors explain why these correlation coefficients are relatively low. SQFFQ tends to overestimate real consumption, especially for the less frequent consumers (Sirot et al., 2008) and when applied to the entire or nearly entire diet (FAO/WHO, 2005). This may lead to relatively high predicted exposures (dietary intake with FCFC or consumption frequency with EWM) compared with the real level of chlordecone found in blood. Blood levels reflect exposure over the past 2 years, whereas the FFQ asked about diet during the last 9 month. In addition FCFC and EMW estimates of intake do not reflect the pharmacokinetic component of the relation between dietary intake and blood concentration or aspects of interindividual variability such as age, genetic characteristics, and nutritional status that may interfere with the chlordecone kinetics and dynamics (FAO/WHO, 1997; Sirot et al., 2008). This is a general issue in this type of validation exercise, estimates of intakes on one hand and biomarkers on the other hand measuring in fact different, although correlated, stages of the exposure process.

In this study, the values predicted by the empirical weight models were better correlated with blood chlordecone levels than were the estimates of chlordecone intake by the FCFC approach. While the consumption data used come from the subjects, it should be underlined that the contamination data used in the FCFC approach are estimates of the average levels of contamination obtained from a limited number of foodstuffs $(n=59)$, not systematically representative of contamination of the foods each women ate. 
Variability of food contamination has not been considered in the calculation of each individual's dietary intake. It was recently suggested (AFSSA, 2007) that food coming from the local distribution network (self-produced, local stores, grocery stores) and markets in the polluted area had significantly higher levels than those from nonpolluted area. Because we had no information about how the women in our study procure food (garden, local purchases, etc.), contamination values at the individual level may have been insufficiently precise. Secondly, recent consumption of highly contaminated food shortly before the blood collection cannot be ruled out. This consumption might not be representative of the basal level of dietary intake; it would affect the chlordecone levels in blood and interfere with the relationship between basal dietary intake and blood level.

Finally, some assumptions had to be made about the contamination level of foods for which chlordecone levels was unavailable. We attributed to some food the contamination level of a similar item (beef for veal, for example) or considered some to be potentially contaminated due to possible local production. The fact that low fat milk (whose contamination has not been determined - the LOD of the measurement technique is attributed to it as a replacement value) is considered to contribute to $0.8 \%$ of the total dietary intake shows the impact of such assumptions. The accuracy of the FCFC approach for interpretation at individual level can be improved by determining the contamination level of foods consumed by the individuals before taking blood samples. Duplicate diet methods answer such question but are rarely used because of their expense (USFDA/WHO, 1999).

Yautia, which was identified as a significant predictor of chlordecone exposure here, had been previously identified as a major contributor to food exposure (AFSSA, 2005, 2007), as well as cucumber (AFSSA, 2005; AFSSA, 2007) and watermelon (AFSSA, 2005). Onions (AFSSA, 2007) and crustaceans (Coat et al., 2006) have both been found to be contaminated by chlordecone in monitoring studies. We cannot rule out the possibility that the selection of some food in the EWM as positively or negatively associated with blood chlordecone levels may be due to their correlation with other potential predictors in dietary patterns. A detailed analysis of dietary profiles will be needed to explain these potential intercorrelations.

\section{CONLCUSIONS}

Two different approaches were used to estimate chlordecone exposure from a food frequency questionnaire. Estimates showed significant positive correlations with blood chlordecone concentration, providing a valid tool for ranking women according to their chlordecone exposure. Such a strategy may be used to study the potential health impact of chlordecone exposure in further surveys. It could be refined by using more precise dietary intake estimation at the individual level. In view of special features in the diet of pregnant women, this validation should also be conducted for other population subgroups.

\section{Disclaimer:}

The findings and conclusions in this paper are those of the authors and do not necessarily represent the views of the French Food Safety Agency. The authors declare they have no conflict of interests.

\section{Acknowledgments}

We thank E. Delver, J. Goudou, O. Vintam, G. Soliveau, E. Janky, P. Lancelot, midwives, and maternity staff from the University hospital of Grande-Terre and the general hospital of Basse-Terre for data collection and recovery. We thank A. Aubert, M.L. Bidondo, M.A. Charles, C. Chevrier, V. Deschamps, A. Forhan, A. Saoudi, H. Sarter, A. Thiebaut, J.L. Volatier, and A. Zeghnoun for assistance with nutritional, toxicological, analytical, and statistical considerations, and M. Louvet for the chlordecone analysis.

Funding sources: This work was supported by grants from the National Institute of Health and Medical Research (Institut National de la Sante et de la Recherche Médicale-INSERM), the National Research Agency (Agence Nationale de la Recherche-ANR), the French Agency for Environmental and Occupational Health Safety (Agence Française de Sécurité Sanitaire de l'Environnement et du Travail-AFSSET), The National Endocrine Disruptor Research Program of the French Ministry of Environment, the Departmental Public Health Services of Guadeloupe (Direction de la Santé et du Développement Social-DSDS), the General Health directorate (Direction Générale de la Santé_-DCS), and the National Institute for Public Health Surveillance (Institut de Veille Sanitaire, InVS).

The Ethics Committee of Guadeloupe approved this study on September 5, 2004. Subjects gave written consent. Parental consent was also required for subjects younger than 18 years.

\section{References}


Published in : Environmental Research

Status: Postprint (Author's version)

AFSSA. Premiere evaluation de l'exposition alimentaire de la population martiniquaise au chlordecone: propositions de limites maximales provisoires de contamination dans les principaux aliments vecteurs. 39. 2005. Maison Alfort, France, Agence Francaise de Securite Sanitaire des Aliments. 2005

AFSSA. Actualisation de l'exposition alimentaire au chlordecone de la population antillaise. Evaluation de l'impact de mesures de maitrise des risques. Document technique AQR/FH/2007-219. 2007; 79.

Bordet, F., Thieffine, A., Mallet, J., Heraud, F., Blateau, A., Inthavong, D., 2007. Inhouse validation for analytical methods and quality control for risk evaluation of chlordecone in food. Int. J. Environ. Anal. Chem. 87, 985-998.

Cabidoche, Y.M., Jannoyer, M., Vanniere, H. Conclusions du Groupe d'Etude et de Prospective « Pollution par les organochlores aux Antilles », aspects agronomiques. Contribution CIRAD INRA. 2006

Cannon, S.B., Veazey Jr., J.M., Jackson, R.S., Burse, V.W., Hayes, C., Straub, W.E., Landrigan, P.J., Liddle, J.A., 1978. Epidemic kepone poisoning in chemical workers. Am. J. Epidemiol. 107, 529-537.

Cellule interregionale d'epidemiologie Antilles Guyane. Pesticides organochlores et sante publique aux Antilles francaises. Bull. Alerte Surveillance Antilles Guyane; Juin 2005, No. 8, 13

Coat, S., et al., 2006. Contamination of some aquatic species with the organochlorine pesticide chlordecone in Martinique. Aquat. Living Resour. 19, 181-187.

Cohn, W.J., Boylan, J.J., Blanke, R.V., Fariss, M.W., Howell, J.R., Guzelian, P.S., 1978. Treatment of chlordecone (Kepone) toxicity with cholestyramine. Results of a controlled clinical trial. N. Engl. J. Med. 298, 243-248.

Debier, C., Pomeroy, P., Dupont, C., Joiris, C., Comblin, V., Le Boulenge, E., Larondelle, Y., Thome, J.P., 2003. Quantitative dynamics of PCB transfer from mother to pup during lactation in UK grey seals Halichoerus grypus. Mar. Ecol. Prog. Ser. 247, $237-248$.

Dubuisson, C., Heraud, F., Leblanc, J.C., Gallotti, S., Flamand, C., Blateau, A., Quenel, P., Volatier, J.L., 2007. Impact of subsistence production on the management options to reduce the food exposure of the Martinican population to Chlordecone. Regul. Toxicol. Pharmacol. 49, 5-16.

FAO/WHO, 1997. Food consumption and exposure assessment of chemicals. WHO/FSF/FOS/97.5. Report of a FAO/WHO Consultation Geneva, Switzerland 10-14 February 1997, World Health Organization, 69pp.

FAO/WHO, 2000. Document WHO/SDE/PHE/FOS/00.5. Proceedings of the Joint FAO/WHO Workshop on Methodology for Exposure Assessment of Contaminants and Toxins in food. Word Health Organization, Geneva, Switzerland, 7-8 June 2000, 20pp.

FAO/WHO, 2005. A model for establishing upper levels of intake for nutrients and related substances. Report of the Workshop on Nutrient Risk Assessment, WHO Headquarters, Geneva, Switzerland, 2-6 May 2005, 241pp.

Faroon, O., Kueberuwa, S., Smith, L., DeRosa, C., 1995. ATSDR evaluation of health effects of chemicals. II. Mirex and chlordecone: health effects, toxicokinetics, human exposure, and environmental fate. Toxicol. Ind. Health 11, 1-203.

Gellert, R.J., 1978. Kepone, mirex, dieldrin, and aldrin: estrogenic activity and the induction of persistent vaginal estrus and anovulation in rats following neonatal treatment. Environ. Res. 16, 131-138.

Gomez-Catalan, J., et al., 1991. Transport of organochlorine residues in the rat and human blood. Arch. Environ. Contam. Toxicol. 20.

Guzelian, P.S., 1992. The clinical toxicology of chlordecone as an example of toxicological risk assessment for man. Toxicol. Lett. 64-65 (Spec. No.), 589-596.

Health Canada. Canadian Nutrient File, 2007, http://www.hc-sc.gc.ca/fn-an/ nutrition/fiche-nutri-data/index-fra.php. 2007. Hercberg, S., 2005. In: Tables de composition des aliments SU.VI.MAX. Economica, Paris.

Hercberg, S., Deheeger, M., Preziosi, P.S.U.-V.I.-M.A.X., 1994. In: Portions alimentaires. Manuel photos pour l'estimation des quantites. Polytechnica, Paris

Lubin, J.H., Colt, J.S., Camann, D., Davis, S., Cerhan, J.R., Severson, R.K., Bernstein, L., Hartge, P., 2004. Epidemiologic evaluation of measurement data in the presence of detection limits. Environ. Health Perspect. 112, 1691-1696.

MacIntosh, D.L., Williams, P.L., Hunter, D.J., Sampson, L.A., Morris, S.C., Willett, W.C., Rimm, E.B., 1997. Evaluation of a food frequency questionnaire - food composition approach for estimating dietary intake of inorganic arsenic and methylmercury. Cancer Epidemiol. Biomarkers Prev. 6, 1043-1050.

Mactutus, C.F., Tilson, H.A., 1984. Neonatal chlordecone exposure impairs early learning and retention of active avoidance in the rat. Neurobehav. Toxicol. Teratol. 6, 75-83.

Mactutus, C.F., Unger, K.L., Tilson, H.A., 1984. Evaluation of neonatal chlordecone neurotoxicity during early development: initial characterization. Neurobehav. Toxicol. Teratol. 6, 67-73.

Multigner, L., 2006. Pesticides organochlores aux antilles: etat d'avancement des etudes epidemiologiques. Bull. Alerte Surveillance Antilles Guyane 2006,9.

Multigner, L., Cordier, S., Kadhel, P., Huc-Terki, F., Blanchet, P., Bataille, H., Janky, E., 2007. Pollution par le chlordecone aux Antilles Quel impact sur la sante de la population? Environ. Risques Sante 6, 405-407.

Multigner, L., Kadhel, P., Huc-Terki, F., Thome, J., Janky, E., Auger, J., 2006. Exposure to chlordecone and male fertility in Guadeloupe (French West Indies). Epidemiology 17, S372.

Riederer, A.M., Bartell, S.M., Barr, D.B., Diet, Ryan PB., 2008. nondiet predictors of urinary 3-phenoxybenzoic acid in NHANES 19992002. Environ. Health Perspect 116, 1015-1022.

Romieu, I., Stampfer, M.J., Stryker, W.S., Hernandez, M., Kaplan, L., Sober, A., Rosner, B., Willett, W.C., 1990. Food predictors of plasma beta-carotene and alpha-tocopherol: validation of a food frequency questionnaire. Am. J. Epidemiol. 131, 864-876. 
Published in : Environmental Research

Status: Postprint (Author's version)

Sirot, V., et al., 2008. Methylmercury exposure assessment using dietary and bio-marker data among frequent seafood consumers in France CALIPSO study. Environ. Res. 107, 30-38.

Soine, P.J., et al., 1982. Preferential binding of chlordecone to the protein and high density lipoprotein fractions of plasma from humans and other species. J Toxicol. Environ. Health. 9, 107-118.

Taylor, J.R., Selhorst, J.B., Houff, S.A., Martinez, A.J., 1978. Chlordecone intoxication in man. I. Clinical observations. Neurology 28, 626630.

Tobin, J., 1958. Estimation of relationships for limited dependant variables. Econometrica 26, 24-36.

USDA. USDA National Nutrient Database for Standard Reference, Release 20. http://www.nal.usda.gov/fnic/foodcomp/search/. 2007.

USFDA/WHO, 1999. Consultations and Workshops, GEMS/Food Total Diet Studies, Reports of a Joint USFA/WHO International

Workshop on Total Diet Studies in cooperation with the Pan American Health Organisation, World Health Organisation, Kansas City, USA, 1999

Willett, W.C., 1998a. In: Food-Frequency Methods. Use of Empirical Predictor Score. Nutritional Epidemiology second ed Oxford University Press, pp. 88-89.

Willett, W.C., 1998b. In: Nutritional Epidemiology second ed Oxford University Press, USA.

Zeghnoun, A., Pascal, M., Fréry, N., Sarter, H., Falq, G., Focant, J., Eppe, G., 2007. Dealing with the non-detected and non quantified data. The example of the serum dioxin data in the french dioxin incinerator study. Organohalogen Compd. 69, $2288-2291$. 